KERNFORSCHUNGSZENTRUM

KARLSRUHE

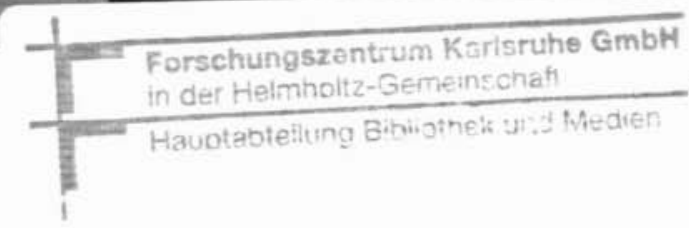

Institut für Radiochemie

Simultaneous Diffusion of Argon and Krypton in Single Crystals of $\mathrm{KCl}-\mathrm{RbCl}$

P. Schmeling, R. Schroerschwarz

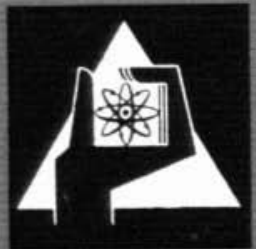





\author{
phys. stat. sol. 15, 325 (1966)
}

Institut für Radiocheme, Kernforschungszentrum Karlsruhr

\title{
Simultaneous Diffusion of Argon and Krypton in Single Crystals of $\mathrm{KCl}-\mathrm{RbCl}$
}

\author{
By \\ P. Schmeling and R. Schroerschwarz
}

\begin{abstract}
The simultaneous diffusion of $A \mathrm{r}^{41}$ and $\mathrm{Kr}^{80} \mathrm{nl}^{\mathrm{n} 1}$ into single crystals contaning 30 mole percent of $\mathrm{KCl}$ and 70 mole percent of $\mathrm{RbCl}$ is studied. The rare-gases are created by irradiation with fast neutrons. The diffusion kinetics are similar to those of the sirstems $\mathrm{KCl} / \mathrm{Ar}$ and $\mathrm{RbCl} / \mathrm{Kr}$. The interesting high temperature region is characterized by activation energies of $(0.28=0.035) \mathrm{eV}$ and $(0.56=0.035) \mathrm{el}$ for $\mathrm{KCl}-\mathrm{RbCl} / \mathrm{Ar}$ and $\mathrm{KCl}-\mathrm{RbCl} / \mathrm{Kr}$. respectively. The diffusion coefficients of argon are about one order of magnitude higher than those of krypton. Comparison with experiments performed after irradiation to high neutron doses shows that these values are not affected by radiation damage.
\end{abstract}

Die gleichzeitige Diffusion von $\mathrm{Ar}^{41}$ und $\mathrm{Kr}^{\mathrm{N.n} 11}$ wurde in Einkristallen untersucht, die $30 \mathrm{Mol}^{\circ} \mathrm{KCl}$ und $70 \mathrm{Mol}^{\circ}{ }_{0} \mathrm{RbCl}$ enthielten. Die Edelgase wurden durch Bestrahlung mit sehnellen Neutronen erzeugt. Fs ergab sich, daß die Kinetik der Diffusion ahnlich der in den Systemen $\mathrm{KCl} / \mathrm{Ar}$ und $\mathrm{RbCl} \mathrm{Kr}$ war. Der interessierende Hochtemperaturbereich wurde durch Aktivierungsenergien von $(0.28+0.035) \mathrm{el}$ fur Argon in $\mathrm{KCl}-\mathrm{PbCl}$ und $(0,56 \pm 0,035) \mathrm{eV}$ fur Krypton in $\mathrm{KCl}-\mathrm{RbCl}$ charakterisiert. Die Diffusionskoeffizienten des Argons waren ungefahr um einen Faktor 10 größer als die des Kryptons. Ein Vergleicli mit Experimenten an Kristallen, die mit einer hohen Neutronendosis bestrahlt waren. zeigte, daß diese Werte nicht durch Bestrahlungsschäden beeinflußt waren.

\section{Introduction}

The diffusion of argon in pure potassium chloride and of krypton in pure rubidium chloride has been studied previously [1. 2]. In both cases an interstitial diffusion mechanism seems probable in the high temperature region beginning 250 to $300^{\circ} \mathrm{C}$ below the melting point. As mixed crystals of $\mathrm{KCl}-$ RbCl are produced as large single crystals, this material is suitable for the study of the simultaneous diffusion of argon and krypton in the same lattice. The influence of the atomic size of the rare-gas atom upon the activation energy of the diffusion process is of considerable interest in this connection and the aim of this study was to determine this influence by experiment.

\section{Experimental Procedure}

Single crystals containing $70 \mathrm{~mol}^{\circ}{ }_{0}$ rubidium chloride and $30 \mathrm{~mol}{ }^{\circ}$ potassium chloride were used. An analysis showed the presence of $<10^{-5}$ wto , Mg. $2 \times 10^{-4}$ wto ('a. $8 \times 10^{-4}$ wto Sr. $4 \times 10^{-1}$ wt ${ }^{\circ} \circ$ Ba. $4 \times 10^{-1}$ wto ${ }_{0}^{\circ} \mathrm{Na}$, and traces of Li. Cs. Al. Cu, Fe. and Si. In one series of experiments. parallelepipedic. specimens with approximate dimensions $0.5 \times 1 \times 1 \mathrm{~cm}^{3}$ were irradiated through $0.1 \mathrm{~cm}$ cadmium to as low neutron dose as possible in order to aroid an influence of radiation damage $[11$. All irradiations were performed in the FR2 reactor for $10 \mathrm{~min}$ in a thermal neutron flux of $3 \times 10^{13} \mathrm{~cm}^{-2} \mathrm{~s}^{-1}$ (integrated fast dose about $9 \times 10^{14} \mathrm{~cm}^{-2}$ ) and produced $8.4 \times 10^{4} \mathrm{ipm}$ of $\mathrm{Ar}^{41}$ and $2.4 \times 10^{4} \mathrm{ipm}$ of $\mathrm{Kr} \mathrm{r}^{\times 5 \mathrm{~m}}$ per $\mathrm{g}$ material at the end of the irradiation. In a second series of experi- 
ments the crystals were irradiated to an integrated fast dose of about $10^{18} \mathrm{~cm}^{-2}$, creating $\mathrm{Ar}^{39}$ and $\mathrm{Kr}^{85}$ as well.

The irradiated specimen was dropped into the hot zone of the furnace and isothermally annealed in a closed and evacuated system to which an activated charcoal trap $\left(77^{\circ} \mathrm{K}\right)$ was connected. The trap adsorbed the released rare-gas and served as a pump in order to uphold the vacuum of the system. After a certain time at temperature a second trap was connected to the system, and the first one was disconnected, heated, and flushed with helium. The gas mixture was led through an activated charcoal bed $\left(195^{\circ} \mathrm{K}\right)$ with a diameter of $0.6 \mathrm{~cm}$ and a length of $15 \mathrm{~cm}$ in order to selectively adsorb $\mathrm{Kr}^{85 \mathrm{~m}}$. With a gas velocity of $280 \mathrm{~cm}^{3} \mathrm{~min}^{-1}$ the $A \mathrm{r}^{41}$ had a hold-up time less than 1 min whereas the $K \mathrm{r}^{85} \mathrm{n}$ needed $>30 \mathrm{~min}$ to break through the bed. The helium was allowed to pass the trap for $4 \mathrm{~min}$, and the argon was adsorbed in a second charcoal trap $\left(77^{\circ} \mathrm{K}\right)$. Both traps were subsequently heated and the contents of each were transferred to standard gas containers fitted with $0.005 \mathrm{~cm}$ aluminium windows. Each container was measured every second hour with a proportional counter, and the purity of the sample was thus controlled by measuring the half life of the raregas. The quantity of gas collected was determined at a common time. Many gas samples were taken at each isothermal experiment and at the end of the run the specimen was melted in order to drive off all residual gas. About 15 gas samples of both $\mathrm{Ar}^{11}$ and $\mathrm{Kr}^{85 \mathrm{~m}}$ were collected in one experiment. The quantity of rare-gas initially present was determined by adding the measured activities, and the experimentally determined quantity was thus the fraction of gas release, $F$, as a function of the annealing time, $t$.

\section{Results}

The evaluation of the data has been described previously $[3,4]$ and does not require a detailed discussion here. The release curves were plotted $F^{2}$ vs. $t$, and for higher values of $F^{2}$ appropriate corrections were made by transferring $F^{2}$ into the function $\varphi^{2}$ [4]. A straight-line relationship is expected in case of ideal diffusion behaviour.

The release kinetics was closely resembling the ones observed in the system $\mathrm{KCl} / \mathrm{Ar}[1]$ and $\mathrm{RbCl} / \mathrm{Kr}$ [2]. A typieal release eurre is shown in Fig. 1. Both

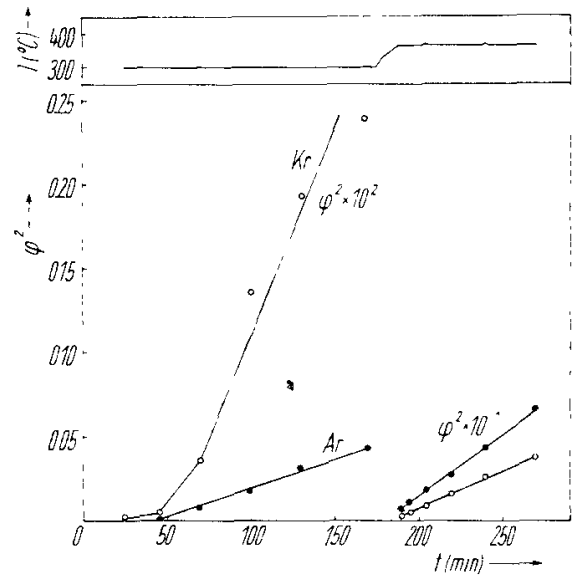

Fig 1 Release curves from a typical nulti-tempera* ture experiment. The specunen had the dimensions $056 \times 1.09 \times 1.12 \mathrm{~cm}^{3}$ and was irrallated to an integrated neutron dose of $9.10^{4} \mathrm{~cm}^{-2}$ 
argon and krypton exhibit admissible straight lines at $300{ }^{\circ} \mathrm{C}$ though the release during the first $30 \mathrm{~min}$ is too low to fit the curve. This behaviour is typical for the diffusion of argon in $\mathrm{KCl}$ at intermediate temperatures and can formally be regarded as an increase of the value of $D$ during an isothermal anneal [1]. At higher temperatures the value of $D$ is constant throughout the anneal in accordance with ideal diffusion kinetics; this seems to be the case already at $375^{\circ} \mathrm{C}$ (Fig. 1).

The diffusion coefficients calculated from all experiments after irradiation to an integrated fast dose of $9 \times 10^{14} \mathrm{~cm}^{-2}$ are plotted in the Arrhenius diagram of Fig. 2. The high temperature region of interest for this investigation begins 250 to $300{ }^{\circ} \mathrm{C}$ below the melting point. In case of diffusion of $\mathrm{Kr}^{85 \mathrm{~m}}$ the best line fitting the points at 350 to $700^{\circ} \mathrm{C}$ has the equation

$$
-\log D=(2.52 \pm 0.2)+(0.56 \pm 0.035) / k T \text {. }
$$

The best equation for the diffusion of $A r^{11}$ in the same temperature interval is

$$
-\log D=(2.89 \pm 0.3)+(0.3 \pm \pm 0.044) / k T \text {. }
$$

As the measured diffusion coefficients of argon vary considerable in the region 350 to $400{ }^{\circ} \mathrm{C}$, the mean value above $400{ }^{\circ} \mathrm{C}$ is here considered as being more accurate:

$$
-\log D=(3.25 \pm 0.2)+(0.28 \pm 0.035) / k T .
$$

As it is known that the diffusion of argon in $\mathrm{KCl}$ is influenced by radiation damage [1], some experiments were performed with erystals irradiated to a fast dose of about $10^{18} \mathrm{~cm}^{-2}$. It happened that the crystal broke into pieces during the anneal, indicating a definite change of the mechanical properties after irradiation to this dose, and the experiment had to be discarded. The results from a few successful experiments are shown in Fig. 3. However. in view of these experimental difficulties it was felt unwise to estimate the error of the ralue of $D$, and the experimental points have not been used for the calculation of the activation energy.

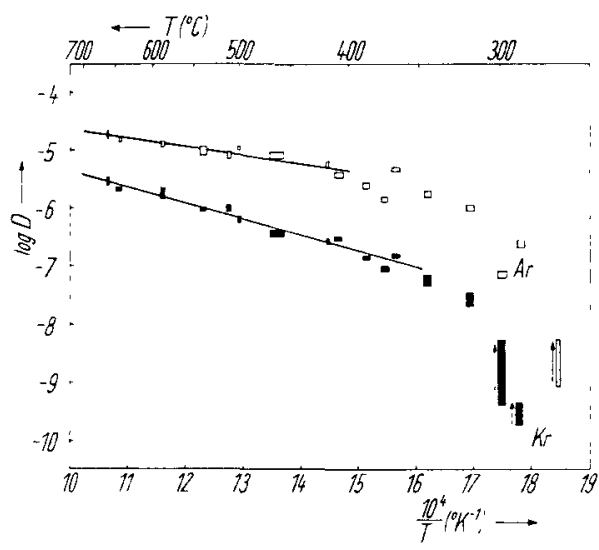

Fig. :-. Arrhenius plot with expermental points for quecimeis irradiated to $9,10^{14} \mathrm{~cm}^{-2}$. The drawn lines correspond to equations (1) and (3). The arrows ind cate that the observed diffusion coeficient has increased during the isothermal anneal

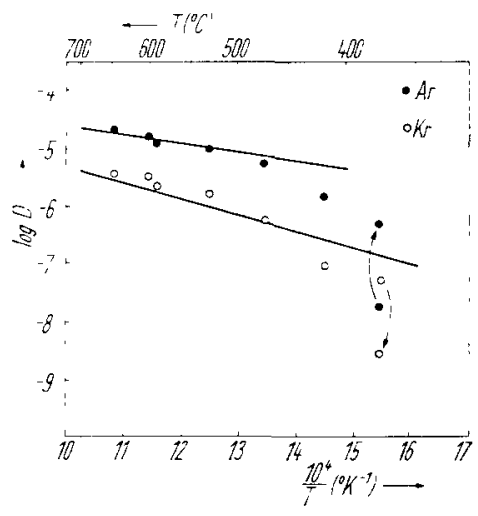

Fig. 3. Arrhentus plot with experinental points for specimens jrradiated to about $10^{18} \mathrm{cmi}^{-2}$. Tlik dian lines are the same as in Fig. 2 and correspond to equations (1) 


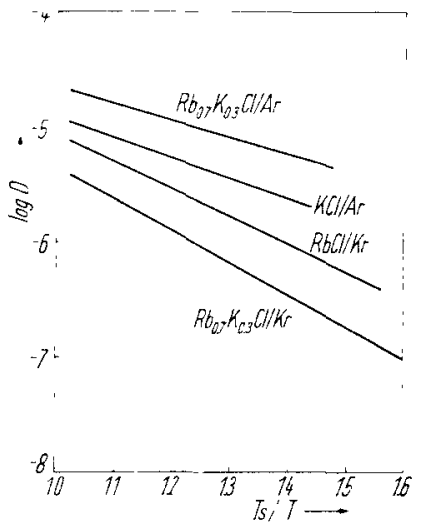

Fis. 4. Arrlenius plot covering the present results on mixcd crystals of $\mathrm{KCl}-\mathrm{RbCl}$ together with previous results reported on the systenis $\mathrm{KCl} / \mathrm{Ar}$ and $\mathrm{RbCl} / \mathrm{Kr}[1,2]$. In order to facilitate a comparison, log $D$ is plotted against $T_{8} / T$, where $T_{8}$ is the melting point $\left({ }^{\circ} \mathrm{K}\right.$ ) of the investigated material

\section{Diseussion}

At high temperatures the values of $D$ seem to coincide regardless of the received neutron dose (Fig. 3). The activation energies given in equation (I) and (3) should therefore be valid for diffusion in the undisturbed lattice. The decrease of $D$ at lower temperatures is consistent with measurements of argon diffusion in radiation damaged $\mathrm{KCl}[1]$.

The results are compared with the systems $\mathrm{KCl} / \mathrm{Ar}$ and $\mathrm{RbCl} / \mathrm{Kr}$ in Fig. 4. A comparison is advantageous as all specimens were irradiated in the same irradiation channel of the FR2 reactor and the experimental procedure was practically identical.

The diffusion coefficients of argon in pure $\mathrm{KCl}$ are quite close to those of krypton in pure RbCl [1,2] (Fig. 4). The lattice of the mixed crystals is more spacious than that of $\mathrm{KCl}$ and as expected the argon diffuses easier in the former. Similarly. krypton diffuses easier in pure RbCl than in the mixed crystals. Though the rarlii of argon and krypton are only slightly different (1.92 and $1.98 \mathrm{~A}$ ). the diffusion coefficients differ with about one order of magnitude (Table 1). The transport velocity thus seems sensitive to the size of the diffusing atom.

Table 1

Comparison of diffusion coefficients and activation energies (cf. Fig. 4)

\begin{tabular}{lccc}
\cline { 3 - 3 } \multicolumn{1}{c}{ System } & $\begin{array}{c}\text { Activation } \\
\text { energy }\end{array}$ & \multicolumn{2}{c}{$\begin{array}{c}\text { Diffusion coefficient } \\
-\log I)\end{array}$} \\
$\mathrm{KCl}-\mathrm{RbCl} / \mathrm{Ar}$ & & $T_{\mathrm{s}} / T=1.10$ & $T_{\mathrm{s}} / T=1.40$ \\
$\mathrm{KCl} / \mathrm{Ar}$ & 0.28 & 4.80 & 5.20 \\
$\mathrm{RbCl} / \mathrm{Kr}$ & 0.38 & 5.10 & 5.60 \\
$\mathrm{KCl}-\mathrm{RbCl} / \mathrm{Kr}$ & 0.44 & 5.30 & 6.00 \\
& 0.56 & 5.65 & 6.45
\end{tabular}

At the present state of knowledge one must assume that the rare gas moves through the lattice according to an interstitial mechanism [1]. When moving from the site $(1 / 4,1 / 4,1 / 4)$ to the neighbour site $(1 / 2,1 / 4,1 / 4)$ a rare-gas atom 
has to be sufficiently activated to overcome the energy barrier in $(3 / 4,1 / 4.1 / 4)$. At this saddle point it is surrounded by four lattice ions, namely two diametrically placed anions and cations respectively. The distance anion-anion and cation-cation is thus of importance for the value of the activation energy of the diffusion process, and this distance increases in the order $\mathrm{KCl}$. RbCl- $\mathrm{KCl}$. and $\mathrm{RbCl}$. Qualitatively the value of $Q$ should be larger in $\mathrm{KCl}$ than in $\mathrm{RbCl}-\mathrm{KCl}$ for argon diffusion, and be larger in RbCl-KCl than in RbCl for krypton diffusion. This is verified by the experiments and the relative change in activation energy is considerable (cf. Table 1).

\section{Aclinowledgement}

The authors would like to thank Prof. W. Seelmann-Eggebert, Director of the Institute, for his encouragement of this work.

\section{Reforences}

[1] P. Scmineling, phys. stat. sol. 11. $175(196.5)$.

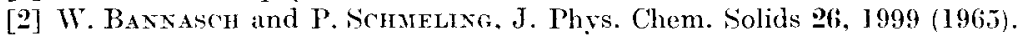

[3] W. Ixtmoff and K. E. Znuex. Kinetik der Diffusion radioaktwer Edelgase aus festen Stoffen nach Bestrahlung, Trans. Chalmers Gnw. Techn., No. 176. Gumperts, Goteborg 1956 .

[4] T. Lagierwall. Diffusion und Einfanær von Argon on neutronbestrahltem Kalziumfluorid, Trans. Chalmers Cnir. Techn., No. 307. (iumperts, Gotebore 1965. 